\title{
A rolling blackout oral cavity
}

\author{
L. Thapa ${ }^{1}$, R. Paudel ${ }^{1}$, A. Basnet ${ }^{2}$, R. Shilpakar ${ }^{2}$, P. C. Majhi ${ }^{3}$, P. V.S. Rana ${ }^{1}$ \\ ${ }^{1}$ Department of Neurology, ${ }^{2}$ Department of Internal Medicine, ${ }^{3}$ Department of Anesthesia, College of Medical Sciences- \\ Teaching Hospital, Chitwan, Nepal
}

\begin{abstract}
We have heard of rolling black outs as a staple of daily life in many Asian countries. We from Nepal, a country suffering rolling blackout, present a case that we refer as "Rolling blackout oral cavity". Aspiration of gastric and oral content into airway is a well known complication during endotracheal intubation but aspiration of a part of equipment during the procedure is rare. We report a case of lost bulb of laryngoscope during endotracheal intubation.
\end{abstract}

Keywords: Endotracheal intubation, foreign body, laryngoscope bulb

We have heard of rolling black outs as a staple of daily life in many Asian countries. We from Nepal, a country suffering rolling blackout, present a case that we refer as "Rolling blackout oral cavity".

Aspiration of gastric and oral content into airway is a well known complication during endotracheal intubation but aspiration of a part of equipment during the procedure is very rare. We report a case of lost bulb of laryngoscope during endotracheal intubation in a neurology patient. Few cases have been reported in pediatric ${ }^{1,2,3}$ and anesthesiology journal ${ }^{4}$ but not in journals commonly referred by general physicians.

A 40 year old male who presented with status epilepticus was diagnosed to have optico-hypothalamic glioma. Because of his low GCS (E1, V1, M4=6/ 15), he was tried for endotracheal intubation under direct laryngoscopy to protect his airway. Unfortunately, the laryngoscope light "went out". It was attributable to poor battery performance in the Correspondences: L. Thapa E-mail:.kushrajt@yahoo.co.in laryngoscope. Immediately he was intubated with help of different laryngoscope. On reexamining the previous laryngoscope, the bulb was found to be missing. Literature that would come to our mind made us think that it must have either been ingested or aspirated. We then tried to explore the oropharynx and hypopharynx but did not find the bulb. We got the X-ray chest done including the abdomen thinking we would localize the bulb. Nothing found! Great! We thought bulb may have fallen on the floor, looked for it but did not find. We had missed the x-ray neck and after getting it done, we could find the bullet shaped bulb in the hypopharynx (Figure 1). We could remove it with Magill's forcep under direct visualization with laryngoscope.

This case is another example among the few existing literatures that alerts us to find instantly the cause of "rolling blackout oral cavity" and the need to verify the integrity of any equipment used in medical practice. Importantly vital equipment like laryngoscope that is used around the airway, should be checked seriously 
L. Thapa et al, A rolling blackout oral cavity

to avoid catastrophic airway problems. And, as general physicians, especially working in resource poor settings, all of us must be aware of this particular complication which is avoidable.

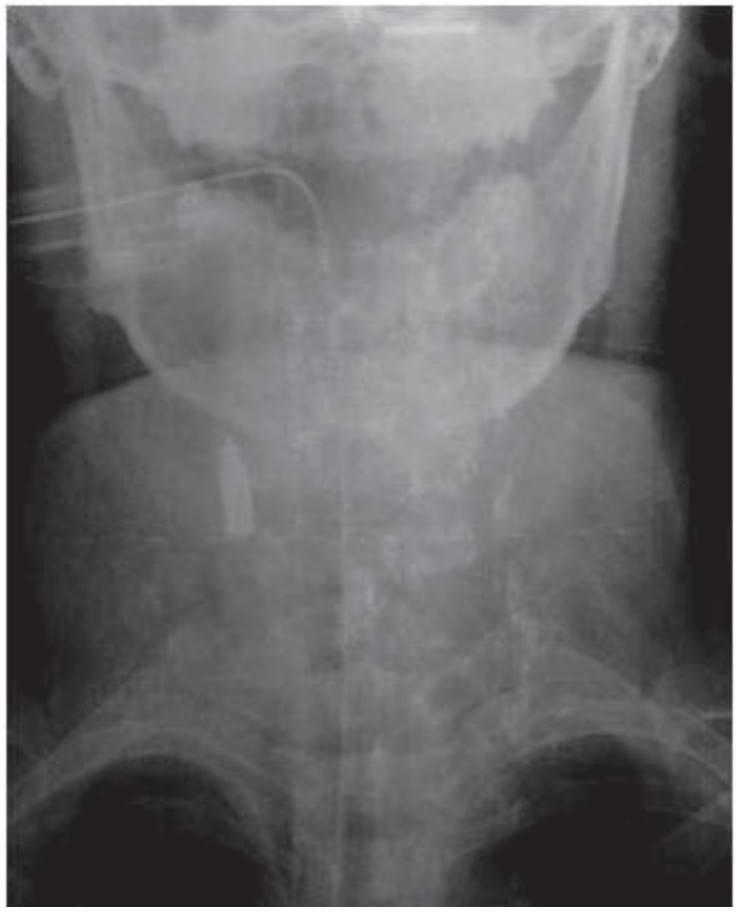

Fig. 1 : A bullet shaped bulb

\section{References}

1. L.Naumovski, K. Schaffer, B. Fleisher Ingestion of a laryngoscope light bulb during delivery room resuscitation. Pediatrics 1991; 87:581-2.

2. Z. Ince, D. Tugcu, A. Coban. An unusual complication of endotracheal intubation: ingestion of a laryngoscope bulb. Pediatr Emerg Care 1998; 14:275-6.

3. S.D. Delport, B.H.Gibson. Ingestion of a laryngoscope light bulb during tracheal intubation. S Afr Med J 1992; 81:579.

4. E.S. Timothy, Daniel d'Hulst, G. Douglas et al WellFertilized Bulb Should Blossom. Anesth Analg 2004; 99:622. 